\title{
LAZER E RECREAÇÃO ASSOCIADOS AOS AMBIENTES AQUÁTICOS NUMA PEQUENA CIDADE DO INTERIOR PAULISTA
}

\author{
Gabriela Marcantônio Dias, Danielli Cristina Granado \\ Universidade Estadual Paulista Júlio de Mesquita Filho - UNESP. Campus de Rosana. Email: danielli@rosana.unesp.br
}

\section{RESUMO}

Os ambientes aquáticos parecem compor as opções de lazer e recreação preferidas da população. Deste modo, este estudo teve como objetivo compreender a relação existente entre a população local urbana e os ambientes aquáticos existentes no Município de Rosana, sobretudo quanto ao uso para lazer e recreação e a atratividade turística. Para alcançar os objetivos foram realizadas entrevistas por meio de amostragem probabilística aleatória. A realidade observada em outros estudos vai de encontro aos resultados desta pesquisa, em que $99 \%$ da população amostrada visita espaços no município de Rosana, que estejam associados ao Rio Paraná e ao Reservatório de Porto Primavera e $48 \%$ tem preferência por este locais em seus momentos de lazer. Os resultados obtidos vão de encontro à hipótese elaborada para esta pesquisa e também as informações existentes na literatura, que referenciam os ambientes aquáticos como locais preferencialmente procurados para lazer, recreação e turismo no mundo todo.

Palavras-chave: ambientes aquáticos, lazer, recreação, turismo.

\section{LEISURE AND RECREATION ASSOCIATED WITH AQUATIC ENVIRONMENTS IN A SMALL CITY OF SÃO PAULO STATE}

\begin{abstract}
Aquatic environments seem to compose the leisure and recreation of the population preferred. Thus, this study aimed to understand the relationship between the local urban population and existing aquatic environments in Rosana (SP), especially regarding the use for leisure and recreation and tourist attractiveness. To achieve the objectives interviews were conducted by means of random probability sampling. The reality observed in other studies meets the results of this survey, in which $99 \%$ of the sampled population visit areas in the municipality of Rosana, which are associated with the Paraná river and Porto Primavera reservoir and $48 \%$ have a preference for this in their local leisure time. The results go against the hypothesis developed for this research and also information from the literature, that reference aquatic environments as preferentially sought for recreation and tourism worldwide locations.
\end{abstract}

Keywords: aquatic environments, leisure, recreation, tourism. 


\section{INTRODUÇÃO}

Os ambientes aquáticos parecem compor as opções de lazer e recreação preferidas em todo o mundo. Várias pesquisas evidenciam essa preferência da população em usufruir de seu tempo livre em locais relacionados a ecossistemas aquáticos (ANA, 2005; BOULLÓN, 2002; CAMARGO, 1992, 1998; PEREIRA et al., 2013). As praias litorâneas são consideradas o produto turístico mais popular em todo o mundo (CAMARGO, 1992, 1998; PEREIRA et al., 2013) e, também são responsáveis por suprir boa parte da demanda de lazer das populações de municípios costeiros (BOULLÓN, 2002).

Segundo o mesmo Autor, nas cidades atravessadas por rios, a poluição e a canalização impede que os mesmos sejam desfrutados para tais usos, sobretudo nas grandes cidades, onde os problemas urbanos aparentam estar cada vez mais distantes de solução. E assim, os rios tornamse verdadeiros esgotos a céu aberto e ao invés de atrair causam repúdio à população.

Entretanto, mais afastadas dos aglomerados urbanos, as paisagens dos cursos de água tentam retomar suas características naturais. E nessas condições, rios e represas passam a atrair visitantes, tanto da localidade, quanto da região onde estão inseridos. Neste cenário, pequenos municípios brasileiros têm se beneficiado de seus ambientes aquáticos como espaços destinados à recreação e ao turismo. Este é o caso do município de Rosana, uma pequena cidade do interior paulista, cuja abundância de águas superficiais possibilita a existência de inúmeros espaços associados aos ambientes aquáticos, os quais são utilizados pela população local e visitantes para lazer e recreação.

Neste âmbito, o presente estudo teve como objetivo compreender a relação existente entre a população local urbana e os ambientes aquáticos existentes no Município de Rosana, sobretudo quanto ao uso para lazer e recreação e a atratividade turística. A hipótese levantada nesta pesquisa pressupõe que as prainhas do Município são os locais mais frequentados pela população urbana nas horas vagas, sendo portanto, as principais opções de lazer para os munícipes. $\mathrm{E}$ as atividades que prevalecem no uso desses espaços estão diretamente relacionadas ao contato direto com a água. Considera-se ainda que, tanto o Rio Paraná, quanto o Reservatório de Porto Primavera e os espaços a eles associados, figuram entre os primeiros atrativos turísticos de Rosana, elegidos pela população. 
O município de Rosana, onde esta pesquisa foi desenvolvida possui 19.691 habitantes (IBGE, 2014). Localiza-se no extremo-oeste do Estado de São Paulo numa região conhecida como Pontal do Paranapanema. Este território, delimitado ao sul pelo rio Paranapanema e a oeste pelo rio Paraná, abrange uma área de $18.441,60 \mathrm{Km}^{2}$, composta por 32 cidades, cuja população total é de 583.766 habitantes, dos quais 59.911 vivem na área rural, o que corresponde a $10,26 \%$ do total. O Índice de Desenvolvimento Humano - IDH médio regional é de 0,80 (SÃO PAULO, 2012).

Considerada a segunda região mais pobre do Estado Paulista, o Pontal é marcado por conflitos fundiários e pela degradação ambiental. Trata-se da região mais recentemente devastada no Estado, transformada em extensas áreas de monocultivos e pastagem (VALLADARES-PÁDUA et al., 2002).

A construção de reservatórios nos dois grandes rios que banham a região também contribuiu para a degradação ambiental. No rio Paranapanema, uma das onze barragens construídas ao longo de seu curso, encontra-se no Pontal do Paranapanema. Já no Rio Paraná, o maior lago artificial, em espelho d'água, desse Rio, denominado reservatório de Porto Primavera, tem grande parte de sua área situada no Pontal do Paranapanema. Operado pela Companhia Energética de São Paulo - CESP, cuja Usina Engenheiro Sérgio Motta, que o opera está instalada no município de Rosana.

Apesar dos diversificados impactos sociais e ambientais gerados por Porto Primavera, que não serão foco deste trabalho, o seu enchimento possibilitou o aparecimento de inúmeras praias em alguns dos municípios banhados por suas águas, inclusive na área rural de Rosana, o local é conhecido como "Prainha do Grêmio", por ficar próximo ao Grêmio, que é o clube recreativo da CESP.

Importante salientar que algumas dessas praias foram construídas pela CESP como compensação ambiental aos impactos causados, até em substituição aos espaços anteriormente usados pela população nas margens da calha natural do Rio, como no caso dos balneários de Anaurilândia (MS) e Presidente Epitácio (SP), entre outros.

A formação do Reservatório resultou também na construção da vila de Primavera, distante 13 quilômetros de Rosana, tinha a função de abrigar trabalhadores da obra da CESP. Atualmente, na vila vive a maior parte dos habitantes do Município, nela também está situado o Fórum, o Hospital Regional e o Campus da UNESP. 
Além das prainhas no reservatório de Porto Primavera, o município dispõe ainda de praias fluviais no trecho lótico do Rio Paraná, como o Balneário Municipal e o bairro Beira Rio. O primeiro é o principal espaço público destinado ao lazer no Município, o qual conta com infraestrutura básica e equipamentos relacionados à recreação como rampa para barcos, parque infantil, quadra de areia, área de camping, lanchonetes e academia para terceira idade (ROSANA, 2012).

A montante do Balneário encontra-se o Beira Rio, um bairro rural, onde inúmeros ranchos de pescadores e residências secundárias situam-se nas margens do Rio Paraná. No local também existem pousadas e bares bastante frequentados por turistas praticantes de pesca.

Para alcançar os objetivos propostos neste trabalho foi utilizado o método de entrevista aplicada por meio de visitas as residências, utilizando um protocolo estruturado. A seleção da amostra de 200 indivíduos da população urbana se deu por amostragem probabilística aleatória. Neste procedimento, a partir do mapa da área urbana, a cidade de Rosana foi dividida em cinco zonas (norte, sul, leste, oeste e centro), em cada zona foram sorteadas quatro quadras ou ruas, onde foram sorteadas cinco casas para aplicação da entrevista a um morador da casa. Cabe destacar que esta pesquisa foi aprovada no Comitê de Ética da Faculdade de Ciência e Tecnologia da Universidade Estadual Júlio de Mesquita Filho - UNESP, Campus de Presidente Prudente (CAAE: 19736213.2.0000.5402).

\section{RESULTADOS}

Os resultados da pesquisa mostraram que dentre os participantes da pesquisa, $99 \%$ declararam frequentar as prainhas de Rosana, em algum momento da vida. E quando questionados sobre os locais que mais visitavam nas horas vagas, como forma de lazer, os entrevistados apontaram os ambientes aquáticos do Município como as áreas preferidas nas horas vagas. Destes, 34\% visitam com mais frequência o Balneário Municipal. Outros locais apontados com certa frequência foram a casa de amigos e parentes (17\%), os bares, lanchonetes e restaurantes (15\%), a Prainha do Grêmio ( $11 \%$ ) localizada no Reservatório de Porto Primavera e a praça (9\%). A visita ao bairro Beira Rio, onde também há uma prainha e ranchos situados nas margens do Rio Paraná, foi a resposta de $3 \%$ dos participantes da pesquisa. Outros locais do Município citados com menos representatividade foram: a feirinha (espaço de exposição onde há um evento semanal às sextas-feiras), a boate, a igreja, o Clube Recreativo Grêmio da CESP, o ginásio e outros locais onde se pode praticar esportes.

Os resultados de frequência às prainhas do Município mostraram que a maior parte da população amostrada (30\%) costuma visitar as prainhas ao menos uma vez por semana, enquanto 
que $28 \%$, as frequentam cerca de duas vezes ao mês, provavelmente em finais de semana e, $17 \%$, apenas quando estão de férias. A frequência aos ecossistemas aquáticos uma vez ao mês foi a resposta de $12 \%$ dos entrevistados e $5 \%$ relatam frequentar as prainhas todos os dias.

Em relação às principais atividades realizadas nas prainhas, $43 \%$ da população amostrada declarou que o banho é a atividade preferida. As outras atividades mais citadas foram a pesca (20\%), a conversa com os amigos (13\%), a natação (11\%) e a contemplação da paisagem (9\%).

Este estudo buscou também conhecer a opinião da população Rosanense, quanto aos atrativos turísticos existentes na Cidade e os resultados mostraram que $55 \%$ dos entrevistados apontaram o Balneário Municipal como principal atrativo aos visitantes, enquanto que $17 \%$ afirmaram ser o próprio Rio Paraná. A pesca foi apontada como chamativo aos turistas por $8 \%$ dos participantes da pesquisa e a Usina Hidrelétrica Engenheiro Sérgio Motta e seu clube conhecido como Grêmio foram lembrados por $4 \%$ da população, cada um. Outros atrativos citados durante a entrevista foram: a paisagem, a fauna e a flora local, as ilhas no Rio Paraná, os eventos realizados no Município, a gastronomia, os ranchos, o encontro dos rios Paraná e Paranapanema, o Campus da UNESP, a ferrovia desativada entre outros locais e elementos.

\section{DISCUSSÃO}

O tempo destinado ao descanso e às atividades livres de obrigações tem relevante valor social desde os séculos XIX e XX, época em que a sociedade se dedicava a longas jornadas de trabalho (DANTAS, 2011). "Desde o nascimento da sociedade industrial, os pensadores sociais do século XIX previram a importância do lazer, ou antes, do Tempo Liberado pela redução do trabalho industrial" (DUMAZEDIER, 1999, p.19-20).

Marcellino (2008a) situa o lazer no sentido mais amplo da cultura vivenciada no tempo disponível. E neste sentido, destaca a busca por satisfação nesta vivência, além dos aspectos tempo e atitude, que possibilitam eleger entre a atividade ou o ócio (MARCELLINO, 2004).

Sob a ótica das funções do lazer, enumera-se o descanso, o divertimento e o desenvolvimento (Dumazedier, 2001), considerados por Marcellino (2008b) os três pilares de sustentação do lazer. A importância do lazer na atualidade pode ser demonstrada por sua presença na Declaração Universal dos Direitos Humanos (FORAUSTIE, 1973). No Brasil, o tema tem sua relevância expressa no Artigo 6ㅇ da Constituição Federal de 1988, que situa o lazer como um dos direitos sociais do povo brasileiro.

A carência por espaços públicos destinados ao lazer para usufruto da população, na maioria dos municípios brasileiros, é em partes suprida pela presença de ecossistemas aquáticos, 
em cidades onde tais ambientes estejam em condições adequadas para este aproveitamento. Este é o caso do município de Rosana, onde espaços associados ao Rio Paraná e ao Reservatório de Porto Primavera propiciam lazer e recreação para a população.

A frequência às prainhas de Rosana foi apontada por $99 \%$ dos entrevistados e entre os locais preferidos para visitação nas horas de lazer, os espaços associados aos ambientes aquáticos representaram quase a metade das respostas, já que a soma dos três locais citados totalizaram $48 \%$ do retorno à questão "Que locais você visita nas horas vagas, como forma de lazer?".

Este resultado corrobora com Camargo (2008), que relata que "as praias, as represas e os rios (ou as piscinas) são o primeiro destino das migrações de fins de semana e férias". A Agência Nacional das Águas - ANA (2005), no documento “O turismo e o lazer e sua interface com o setor de recursos hídricos", publicado em 2005, também destaca os ecossistemas aquáticos como locais preferidos da população brasileira em seus momentos de férias. E aponta o turismo em lagos e reservatórios, como um segmento em expansão no País.

As represas Billings e Guarapiranga são exemplos de ambientes aquáticos que passaram a integrar a paisagem urbana e a ofertar lazer a parte da população paulistana (BRANCO; ROCHA, 1977). Aos finais de semana prolongados, a busca por rios e represas é quase tão intensificada quanto para as áreas litorâneas. Camargo (1998) estima que cerca de 2 milhões de pessoas da região metropolitana se São Paulo se dirigem as águas do complexo Billings - Guarapiranga, enquanto que mais de 3 milhões saem em busca do litoral.

As atividades recreativas nos ambientes aquáticos são classificadas na legislação brasileira em recreação de contato primário, como banho, natação e mergulho; e recreação de contato secundário, como ocorre em alguns esportes náuticos como vela e caiaque. No primeiro caso, 0 padrão de qualidade da água deve ser mais rígido, devido ao contato direto com a água e porque a probabilidade de ingestão de água durante as atividades é muito elevada (BRASIL, 2000; 2005).

Há ainda atividades que são realizadas nas adjacências dos ambientes aquáticos e que não envolvem o contato com a água, como por exemplo, a contemplação da paisagem, o encontro e conversa com amigos, da paquera e piquenique nas margens. No presente estudo, as respostas indicaram que as principais atividades nos ambientes aquáticos do Município são de contato primário. Banho e natação totalizaram $54 \%$ das respostas a este estudo.

Com base nessa constatação, cabe destacar o padrão de qualidade exigido para o tipo de contato primário na recreação, que segundo a Resolução do Conselho Nacional de Meio Ambiente - CONAMA №. 357 de 17 de março de 2005 deve ser realizado em corpos de água enquadrados nas classes 1 e 2, enquanto que para a recreação de contato secundário, os corpos de água de 
classe 3 podem ser utilizados. Corpos de água de classe 4 podem ser destinados apenas à navegação e à harmonia paisagística, devido ao seu padrão inferior de qualidade da água. Este enquadramento realizado por esta Resoluação do CONAMA classifica os ambientes aquáticos, segundo a qualidade requerida para os seus usos preponderantes e salienta no Parágrafo único, do Artigo 3으, que "as águas de melhor qualidade podem ser aproveitadas em uso menos exigente, desde que este não prejudique a qualidade da água, atendidos outros requisitos pertinentes". Cabe destacar ainda, nas Disposições Gerais da Norma:

Art. 7o Os padrões de qualidade das águas determinados nesta Resolução estabelecem limites individuais para cada substância em cada classe.

Parágrafo único. Eventuais interações entre substâncias, especificadas ou não nesta Resolução, não poderão conferir às águas características capazes de causar efeitos letais ou alteração de comportamento, reprodução ou fisiologia da vida, bem como de restringir os usos preponderantes previstos, ressalvado o disposto no § 30 do art. 34, desta Resolução.

Art. 80 O conjunto de parâmetros de qualidade de água selecionado para subsidiar a proposta de enquadramento deverá ser monitorado periodicamente pelo Poder Público (BRASIL, 2005, s/p).

Há ainda na Legislação Brasileira, uma normativa específica para recreação de contato primário ou balneabilidade, trata-se da Resolução do CONAMA №. 274 de 29 de novembro de 2000. Esta norma classifica os ambientes aquáticos como próprios ou impróprios à recreação de contato primário e utiliza como principal indicador de contaminação e risco à saúde dos banhistas, a variável microbiológica.

Assim para garantir que não existam riscos à saúde dos banhistas é necessário que exista um programa de monitoramento nas prainhas utilizadas para recreação de contato primário pela população no Município. Contudo, o que ser observa é a incipiência de tais programas e de informações disponibilizadas a comunidade, não somente em águas interiores, mas nas praias litorâneas também. O monitoramento que no Estado de São Paulo é realizado pela CETESB alcança uma minoria de ambientes aquáticos interiores usados para lazer e recreação, sendo mais efetivo nas áreas costeiras.

Segundo Granado (2014), nas pequenas cidades, o problema se agrava, já que na maioria das vezes não há informações disponíveis, nem estudos que demonstrem a qualidade dos corpos de água usados para lazer e recreação, podendo por em risco a saúde dos banhistas. Esta é a realidade das praias estudadas no município de Rosana, que carecem de um programa voltado à conservação e ao monitoramento de suas águas, que considere os usos múltiplos, principalmente a balneabilidade para fins de lazer e turismo. 
Mas apesar dessa realidade, as informações da literatura apresentadas no início deste artigo mostram que os ambientes aquáticos são locais bastante apreciados pela população brasileira para desfrutar de seus momentos de lazer, principalmente aos finais de semana e períodos de férias. Esta realidade observada em outros estudos vai de encontro aos resultados desta pesquisa, em que $99 \%$ da população amostrada visita espaços no município de Rosana, que estejam associados ao Rio Paraná e ao Reservatório de Porto Primavera e 48\% tem preferência por este locais em seus momentos de lazer.

Os resultados obtidos vão de encontro à hipótese elaborada para esta pesquisa e também as informações existentes na literatura, que referenciam os ambientes aquáticos como locais preferencialmente procurados para lazer, recreação e turismo no mundo todo.

\section{AGRADECIMENTOS}

As Autoras agradecem à Fundação de Amparo à Pesquisa do Estado de São Paulo - FAPESP pela bolsa de estudos concedida à Gabriela Marcantônio Dias (Processo №. 2012/21999-3).

\section{REFERÊNCIAS}

ANA - AGÊNCIA NACIONAL DAS ÁGUAS. Caderno de Recursos Hídricos: o turismo e o lazer e sua interface com o setor de recursos hídricos. Brasília, 2005. Disponível em: http://www.ana.gov.br/pnrh_novo/documentos/06\%20Turismo/VF\%20Turismo\%20Lazer.pdf. Acesso em: 20 de março de 2011.

BOULLÓN, R. C. Atividades turísticas e recreativas: o homem como protagonista. Bauru, SP: EDUSC, 2002.

BRANCO, S. M.; ROCHA, A. A. Poluição, proteção e usos múltiplos de represas. São Paulo: Edgard Blucher, Cetesb, 1977.

BRASIL. CONAMA. CONSELHO NACIONAL DE MEIO AMBIENTE. (2000). Resolução N. 274, de 29 de novembro de 2000. Dispõe sobre a balneabilidade dos corpos de água e dá outras providências. Disponível em: www.planalto.gov.br. Acesso em: maio de 2010.

BRASIL. CONAMA. CONSELHO NACIONAL DE MEIO AMBIENTE. (2005). Resolução N. 357, de 17 de março de 2005. Dispõe sobre a classificação dos corpos de água e diretrizes ambientais para o seu enquadramento, bem como estabelece as condições e padrões de lançamento de efluentes, e dá outras providências. Disponível em: www.planalto.gov.br. Acesso em: maio de 2010.

CAMARGO, L. O. L. O que é lazer. 3a Ed. Coleção Primeiros Passos. São Paulo: Brasiliense, 1992. . Educação para o lazer. Coleção Polemica. São Paulo: Moderna, 1998. 
DANTAS, E. W. C. A Geografia Urbana no Nordeste Brasileiro. In: PEREIRA, E. M.; DIAS, L. C. D. (Orgs.). As cidades e a urbanização no Brasil: passado, presente e futuro. Florianópolis: Insular, 2011, p. 373-403.

DUMAZEDIER, J. Sociologia empírica do lazer. 2.ed. São Paulo: Perspectiva. 1999.

. Lazer e cultura popular. 3.ed. São Paulo: Perspectiva. 2001.

FOURASTIE, J. Ocio y turismo. Barcelona: Biblioteca Salvat de Grandes Temas. 1973.

GRANADO, D. C. Recreação e turismo em reservatórios: a qualidade da água em praias de uma pequena cidade brasileira. Anais do 12. Congresso da Água / 16. ENASB / XVI SILUBESA. Lisboa, Portugal, 2014.

IBGE - Instituto Brasileiro de Geografia E Estatística. Cidades.

(http://cidades.ibge.gov.br/painel/painel.php?codmun=354425 ). Acesso em 20 de janeiro de 2014.

MARCELLINO, N. C. Lazer e sociedade: múltiplas relações. Campinas, SP: Alínea, 2008a.

. Políticas públicas de lazer. Campinas, SP: Alínea, 2008b.

PEREIRA, E. et al. Microbiological and mycological beach sand quality in a volcanic environment: Madeira archipelago, Portugal. Sceince of the Total Environment, 461-462, 2013.

ROSANA, Site da Prefeitura Municipal de Rosana. Disponível em:

http://www.saopaulo.sp.gov.br/conhecasp/turismo_estancias-turisticas. Acesso em: 30 de abril de 2012.

SÃO PAULO, Estâncias turísticas. Disponível em:

http://www.saopaulo.sp.gov.br/conhecasp/turismo_estancias-turisticas. Acesso em: 20 de março de 2012.

VALLADARES-PÁDUA, C. et. al. Módulos agroflorestais na conservação de fragmentos florestais da Mata Atlântica. Revista Experiências PDA, 2, 7-33, 2002. 